\title{
Distinct immediate and prolonged effects of separation on plasma cortisol in adult female squirrel monkeys
}

\author{
SALLY P. MENDOZA \\ California Regional Primate Research Center \\ University of California, Davis, California \\ MICHAEL B. HENNESSY \\ Wright State University, Dayton, Ohio \\ and \\ DAVID M. LYONS \\ California Regional Primate Research Center \\ University of California, Davis, California
}

\begin{abstract}
Adult female squirrel monkeys exhibited reduced plasma cortisol levels $1 \mathrm{~h}$ following separation from their female cagemate. By 6-8 days following separation, however, cortisol levels in these females had increased significantly. When each female was subsequently paired with an unfamiliar female, cortisol levels showed an additional rise $1 \mathrm{~h}$ later and then declined over the following 8 days. The decline could not be accounted for by an increase in affiliation between pairmates or by a decrease in locomotor activity. Furthermore, the decline was comparable for pairs that were and were not observed to fight. These results indicate that separation of adult primates can produce slowly emerging physiological changes that differ from the immediate response to separation, and that social factors other than affiliation appear to regulate endocrine activity in adult female squirrel monkeys.
\end{abstract}

A growing body of evidence links the disruption of social relationships to the development of a variety of pathophysiological processes in humans and other animals (House, Landis, \& Umberson, 1988; O'Leary, 1990). Typically, these effects are attributed to the loss of specific companions or attachment figures, and the social support these individuals provide. The traditional experimental paradigm for studying such effects is that of maternal separation. Following removal of the mother, infants of various species exhibit both behavioral and physiological changes, including increased vocalization rate and locomotor activity, hypothalamic-pituitaryadrenal (HPA) activation, alterations in autonomic and central monoamine activity, and reduced immunocompetence (e.g., Coe, Wiener, Rosenberg, \& Levine, 1985; Reite, Kaufman, Pauley, \& Stynes, 1978; Shapiro \& Insel, 1990; Tamborski, Lucot, \& Hennessy, 1990).

On the basis of work with infant rats, Hofer (1978, 1987) distinguished between effects of maternal separa-

This research was supported by Grant RR00169 from the National Institutes of Health, Division of Research Resources; Grants BNS8701620 and BNS-8822240 from the National Science Foundation to M. B. Hennessy; and National Research Service Award HD07293 to D. M. Lyons. We would like to thank William A. Mason for his contributions to the research. Correspondence should be addressed to $S$. P. Mendoza, California Regional Primate Research Center, University of California, Davis, CA 95616 (e-mail: spmendoza@ucdavis.edu). tion that appear almost immediately following the mother's removal and those that emerge more slowly, taking hours or days for the full effect to become apparent. These short- and long-term effects of separation are not related phases (e.g., protest, despair) of the same ballistic response to removal of the attachment figure. Instead, they have different eliciting conditions and can develop independently of one another.

Effects that emerge immediately following separation of infant and mother (or of other classes of social partners) appear to be due to the removal of the attachment figure per se. Indeed, the magnitude of these responses is often used to evaluate the degree to which the infant (or other individual) is emotionally involved in the relationship (Hofer, 1983; Mendoza, Coe, Smotherman, Kaplan, \& Levine, 1980; Mendoza \& Mason, 1986b; Mineka \& Suomi, 1978; Panksepp, Siviy, \& Normansell, 1985). Effects that develop gradually following maternal separation, on the other hand, seem to result from the removal of specific regulatory influences normally provided by some aspect of maternal stimulation (Hofer, $1978,1987)$. In altricial species such as the rat, for example, newborns are not capable of feeding or thermoregulating by themselves; locomotor skills are not well developed at birth, and pups are born without self-defenses against predation or other environmental hazards (Barnett, 1975). Just as the mother provides the pup with 
nourishment, warmth, and protection, maternal regulation of some aspects of physiological function are also required until the infant approaches maturity. The periodicity of nursing bouts, for instance, influences the interrelations between the infant's sympathetic, parasympathetic, and pituitary-adrenal systems, providing an essential regulatory link in the control of heart rate and blood pressure (Hofer, 1984a). Maternal separation removes this important external regulator of the infant's cardiovascular system, and altered heart rate and blood pressure is apparent 2-3 h later.

The extreme dependency on another specific individual that is characteristic of an altricial infant's relationship with its mother, of course, is rare in other mammalian social relationships. Adult relationships differ from the filial bond in content and consequence. Nonetheless, evidence is beginning to indicate that social regulation of physiological function may be characteristic of fully mature organisms as well as immature organisms with underdeveloped homeostatic mechanisms (Hofer, 1984b). The best example to this point is found in recent research with squirrel monkeys. Preliminary evidence indicates that the presence of like-sex companions alters regulation of the pituitary-adrenal system in adult females (Mendoza, Lyons, \& Saltzman, 1991). When individually housed adult females are formed into isosexual dyads or triads, basal cortisol levels decline over a period of days (Mendoza \& Mason, 1991; Saltzman, Mendoza, \& Mason, 1991). This reduction in HPA activity persists for several months following the formation of new social groups (Mendoza, Saltzman, Lyons, Schiml, \& Mason, 1991), suggesting that negative feedback mechanisms regulating basal activity in this system are altered.

In contrast, the HPA system of these animals appears unresponsive to short-term disruptions of their social relationships. Although mother and infant squirrel monkeys exhibit marked cortisol elevations following a brief period of separation from each other (Mendoza et al., 1980), brief separation of groups of juvenile or adult female squirrel monkeys produces no increase in plasma cortisol levels beyond the response to the disturbance and novelty involved in establishing the separation conditions (Hennessy, 1986; Hennessy, Mendoza, \& Kaplan, 1982). These findings, together with supporting behavioral data (Boinski, 1987; Saltzman, 1991; Tabor, 1986), suggest that female squirrel monkeys do not form an attachment or emotional bond with one another analogous to the mother-infant relationship in this species (Mendoza, Lyons, \& Saltzman, 1991). Nevertheless, the formation of female-female relationships is sufficiently potent to induce long-lasting reductions in circulating glucocorticoids (Mendoza \& Mason, 1991; Mendoza, Saltzman, Lyons, Schiml, \& Mason, 1991; Saltzman et al., 1991).

To date, the long-term response to separation in adult female squirrel monkeys has not been evaluated. If, as Hofer (1987) suggests, withdrawal of regulatory influences is unrelated to immediate response to disruption of relationships, we might anticipate that separation would elicit a gradual increase in HPA activity that is not evident in the immediate responses to loss of social companions. The present study addressed this possibility by assessing the short- and long-term effects of separation on plasma cortisol levels in established pairs of adult female squirrel monkeys. We separated established pairs and monitored plasma cortisol levels over an 8-day period. In order to distinguish loss of an attachment figure from loss of regulatory influences, new dyads were then formed and cortisol levels monitored over an additional 8 days. Because the new partners were unfamiliar, any reduction in cortisol levels at this time could not be attributed to reintroducing the object of an affectional bond. Behavioral measures of affiliation, aggression, and activity in the newly formed pairs were obtained to aid in interpretation of the endocrine results.

\section{METHOD}

\section{Subjects}

The subjects were 12 adult female squirrel monkeys (Saimiri sciureus) of the Colombian and Peruvian varieties. Four monkeys were imported from South America. At the beginning of the study, these animals had been in the laboratory for at least 4 years. The remaining 8 captive-born monkeys ranged in age between 4 and 15 years. The monkeys were pair-housed indoors in standard baskettype primate cages $(0.73 \times 0.77 \times 0.73 \mathrm{~m})$. Opaque partitions precluded visual and tactile contact between animals in different cages, although auditory and olfactory communication were possible. Lighting was on a 12:12-h light:dark schedule (lights on at $0600 \mathrm{~h}$ ). The monkeys were fed a diet of New World monkey chow and water. Pairmates were matched as closely as possible for age, weight, and origin (wild or captive-born). Pairs were housed under these conditions for more than 10 months prior to the initiation of the study.

\section{Design}

The experimental design consisted of three phases: (1) a control phase, (2) a separation phase, and (3) a pair-formation phase. In the control phase, blood samples were collected under undisturbed conditions on Days 1 and 5 to estimate basal cortisol levels of females in established pairs. On Day 4, experimenters captured each member of the pair, briefly held each monkey $(-30 \mathrm{sec})$, and then immediately released them back into their home cage. One hour later, a blood sample was collected. This disturbance procedure was used to control for the effects of disturbance involved in separating monkeys or in forming new pairs.

The separation phase began 2 days following collection of the last blood sample of the control phase. The pairmates were captured, and each member of the pair was placed into a separate clean cage of the same type in the colony room. All animals were accustomed to being rehoused in clean cages as part of colony maintenance procedures so that effects of novelty exposure were likely to be minimal. Blood samples were collected $1 \mathrm{~h}, 25 \mathrm{~h}, 6$ days, and 8 days following separation to determine levels of plasma cortisol.

The pair-formation phase began 4 days following collection of the last blood sample of the separation phase. The females were rehoused as pairs in different cages of the same type. The new pairmates had not been housed together previously. Blood samples were collected 1 h, 25 h, 6 days, and 8 days later to determine the effect of pair formation on cortisol levels.

\section{Blood Sample Collection and Cortisol Analysis}

All blood samples were collected between 0800 and $0900 \mathrm{~h}$. The monkeys were removed from the home cage and manually restrained 
while $2 \mathrm{ml}$ of blood was withdrawn by femoral venipuncture with EDTA as an anticoagulant. Blood samples were obtained serially from all subjects within $4 \mathrm{~min}$ of cage entry (79 $\pm 4 \mathrm{sec}$; mean $\pm S E M)$. The order in which blood samples were obtained was constant within each phase, and the sampling order was maintained as closely as possible between phases. In the control and pairformation phases, samples from pairmates were collected simultaneously. The data were examined to determine whether sampling order influenced the results; in keeping with previous findings from lab-acclimated subjects (Coe, Mendoza, Davidson, et al., 1978; Mendoza \& Mason, 1991), no evidence for order effects was found.

Blood samples were centrifuged to separate plasma, which was stored at $-20^{\circ} \mathrm{C}$ until assayed. The assay method was a competitive binding technique modified from that of Bassett and Hinks (1969), which estimates total glucocorticoids and does not distinguish bound from free hormone. Although this assay measures total cortisol and corticosterone concentrations, comparison of values obtained by this method with those obtained by radioimmunoassay procedures specific for cortisol does not yield significant differences (Cubicciotti, Mendoza, Mason, \& Sassenrath, 1986). Therefore, results are presented with reference to cortisol. Intra- and interassay coefficients of variation were $6.9 \%$ and $10.0 \%$, respectively.

\section{Behavioral Observations}

Behavioral data were collected in the pair-formation phase on Days $1-3,7-9$, and 13-15, using instantaneous scan-sampling procedures. Each pair was observed for $15 \mathrm{~min}$ on each day of observation. The occurrence/nonoccurrence of the following behaviors was noted on the signal at 30-sec intervals: (1) huddling (a species-typical affiliative behavior in which the females sit side by side in physical contact; both animals assume a relaxed posture with tails over their shoulders), (2) other physical contact, and (3) proximity (within one arm's length). To provide a measure of general activity, whether or not the animals were moving (locomotion) was also recorded on the signal. Finally, any observed instances of fighting were noted. All behavioral observations were conducted between 0630 and $0800 \mathrm{hr}$, with the observer sitting quietly about $1 \mathrm{~m}$ from the cage.

\section{Data Analysis}

Data were analyzed with $t$ tests to evaluate the immediate response to altered conditions and one-way analyses of variance (ANOVAs) for repeated measures to evaluate changes within each phase. Post hoc analyses were performed using the Newman-Keuls procedure. For the measures of huddling, other contact, and proximity, the pair was the unit of analysis. One pair of monkeys was disbanded during the pair-formation phase due to excessive fighting. Therefore, their data were not included in the analysis of the changes within the pair-formation phase.

\section{RESULTS}

\section{Cortisol}

An ANOVA of the three cortisol values from the control phase was not significant $[F(2,22)=2.10$, n.s. $]$ (see Figure 1). Cortisol values obtained $1 \mathrm{~h}$ following disturbance were either below or intermediate to the two basal values for all but 2 subjects. Therefore, all three cortisol values from the control phase were averaged for each subject for comparisons with the separation phase.

Separation from a familiar cagemate produced an initial decline in plasma cortisol levels [mean difference = $43.3 \mu \mathrm{g} / \mathrm{dl} ; t(11)=2.88, p=.01$ ] (see Figure 2). Eight of 12 females had lower cortisol values $1 \mathrm{~h}$ following separation from their cagemate than their mean cortisol values during the control phase. In no instance were all three

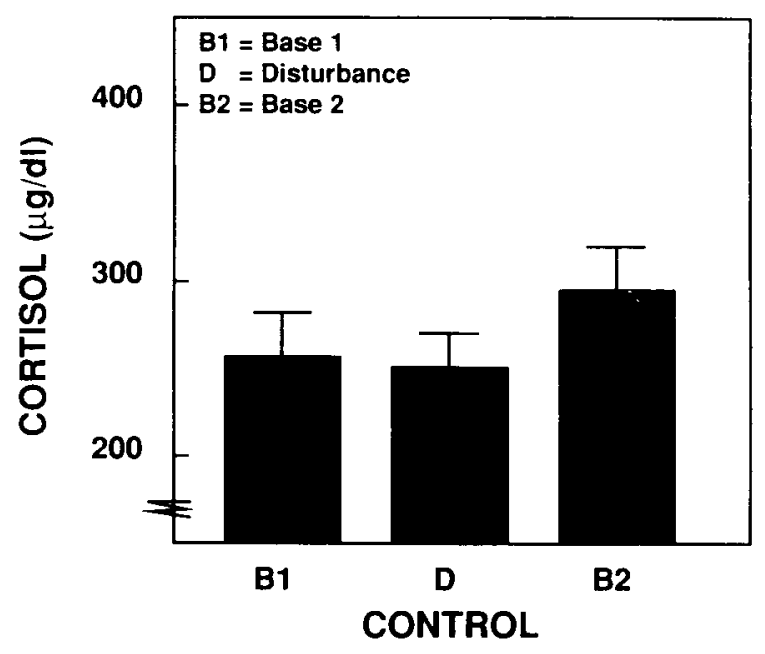

Figure 1. Mean ( $\pm S E M)$ cortisol levels for female squirrel monkeys living in established isosexual pairs (control phase) immediately following capture (Base 1 and Base 2 ) and $1 \mathrm{~h}$ following disturbance procedures.

cortisol values in the control phase lower than cortisol values $1 \mathrm{~h}$ following separation.

Cortisol levels increased significantly during the separation phase $[F(3,33)=4.89, p<.01]$ (see Figure 2 ). Cortisol values for 10 of 12 females were higher on Day 6 than at $1 \mathrm{~h}$ of separation (mean difference $=111.5 \mu \mathrm{g} / \mathrm{dl}$ ) and cortisol levels for 9 of 12 females were higher on Day 6 than at $25 \mathrm{~h}$ following separation (mean difference $=57.5 \mu \mathrm{g} / \mathrm{dl}$ ). By Day 6 , cortisol levels had stabilized: half the animals showed a further increase, and half showed a slight decrease on Day 8. Post hoc analyses confirmed that cortisol levels obtained 6 and 8 days following separation were higher than levels obtained following the first hour of separation ( $p$ s $<.01$ and .05 , respectively). Mean 6-8-day cortisol values were also considerably higher than the mean control phase values (mean difference $=54.4 \mu \mathrm{g} / \mathrm{dl}$ ), but this difference was not statistically significant $[t(11)=1.74, p=.10]$.

Pair formation initially produced an increase in cortisol levels above the mean 6-8-day scores observed at the end of the separation phase [mean difference $=46.1 \mu \mathrm{g} / \mathrm{dl}$; $t(11)=2.82, p<.05$ ] (see Figure 2). One hour following introduction to the new pairmate, cortisol levels for 10 of 12 females were higher than their mean 6-8-day values from the separation phase. In fact, cortisol levels tended to be higher immediately following pair formation than at any other time during the study.

For the five pairs of females that completed the pairformation phase, adrenocortical activity declined during the days following introduction to a new cagemate $[F(3,27)=4.66, p<.01]$ (see Figure 2). Cortisol values for 8 of 10 monkeys were lower on Day 6 than $1 \mathrm{~h}$ following pairing; cortisol values for 9 of 10 monkeys were lower on Day 8 than $1 \mathrm{~h}$ following pair formation. Post hoc tests showed that mean declines from 


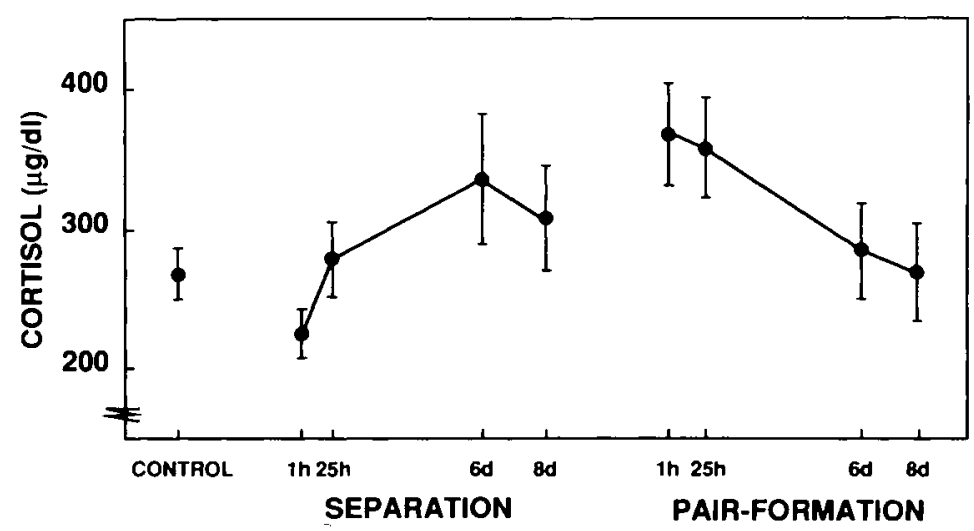

Figure 2. Mean ( $t S E M$ ) cortisol levels for female squirrel monkeys living in established isosexual pairs (CONTROL), 1 h, 25 h, 6 days, and 8 days following separation from their cagemate (SEPARATION), and $1 \mathrm{~h}, 25 \mathrm{~h}, 6$ days, and 8 days following formation of new isosexual pairs (PAIR-FORMATION).

$1 \mathrm{~h}$ to Day 6 and Day 8 were significant $(p s<.05$ ). Cortisol values $25 \mathrm{~h}$ following pair formation were intermediate to those at $1 \mathrm{~h}$ and 6 days and not significantly different from either. By Day 6, cortisol levels had stabilized, however, and Day 8 cortisol levels were slightly, but not significantly, lower than Day 6 levels.

Evaluation of the net decline in adrenocortical activity following pair formation was accomplished by comparing mean 6-8-day cortisol values from the separation phase with mean 6-8-day values from the pair-formation phase. (For the 2 subjects that were disbanded for fighting prior to Day 8 of the pair-formation phase, hormonal values from Day 6 were used in the analysis.) This analysis indicated that cortisol values at the conclusion of the pair-formation phase were significantly lower than cortisol values at the conclusion of the separation phase [mean difference $=42.8 \mu \mathrm{g} / \mathrm{dl} ; t(11)=2.13, p=.05]$. Cortisol values 6-8 days following pair formation were not different from cortisol values during the control phase.

\section{Affiliative and Locomotor Behavior}

Social huddle scores showed a significant change following the formation of new pairs $[F(2,8)=11.88$, $p<.01]$. Huddling was observed more often on Days 1-3 than on Days 7-9 or 13-15 postpairing ( $p$ s $<.01$; see Table 1). There was no change following pairing in

Table 1

Mean ( \pm SEM) Afriliative Behaviors and Locomotion Following Pair Formation

\begin{tabular}{lrcr}
\hline & \multicolumn{3}{c}{ Days After Pair Formation } \\
\cline { 2 - 4 } \multicolumn{1}{c}{ Behavior } & \multicolumn{1}{c}{$1-3$} & $7-9$ & $13-15$ \\
Social Huddle & $25.6 \pm 8.4$ & $8.2 \pm 4.8^{*}$ & $7.4 \pm 5.1^{*}$ \\
Other Contact & $1.8 \pm 0.7$ & $4.8 \pm 4.3$ & $2.6 \pm 2.4$ \\
Proximity & $10.4 \pm 2.6$ & $18.0 \pm 2.7$ & $12.4 \pm 2.7$ \\
Locomotion & $21.4 \pm 5.8$ & $40.5 \pm 7.0^{*}$ & $30.7 \pm 6.0$ \\
\hline
\end{tabular}

*Differs from Days 1-3, $p<.01$. the measures of other contact or proximity. Locomotor activity also varied across observation days $[F(2,18)=$ $6.31, p<.01]$. Post hoc analysis showed that less locomotor activity occurred on Days 1-3 than on Days 7-9 $(p<.01)$.

\section{Fighting and Its Relation to Cortisol}

No fighting was observed during the first 3 days following pairing. The disbanding of one pair for fighting was based on injuries sustained on Day 6 . Two other pairs were seen fighting during observations on Days 7-9. The remaining three pairs showed no wounds or other evidence of fighting at any time during the study. As illustrated in Figure 3, the decline in cortisol levels following pair formation was comparable in pairs for which fighting was and was not detected.

\section{DISCUSSION}

Adult female squirrel monkeys are highly attracted to one another (Mason, 1971) and readily form cohesive subunits within their larger social groups ( Coe \& Rosenblum, 1974; Fairbanks, 1974; Leger, Mason, \& Fragaszy, 1981). Despite their apparent cohesiveness, behavioral and physiological evidence suggests that female squirrel monkeys do not form attachment or emotional bonds with one another that resemble the mother-infant bond (Mendoza, Lyons, \& Saltzman, 1991). Short-term separation of mothers and infants produces cortisol elevations in several species, including squirrel monkeys (Coe, Mendoza, Smotherman, \& Levine 1978; Hennessy \& Ritchey, 1987; Hennessy \& Weinberg, 1990; Mendoza, Smotherman, Miner, Kaplan, \& Levine, 1978; Smotherman, Hunt, McGinnis, \& Levine, 1979). In addition, adult male and female titi monkeys, which form strong monogamous pair bonds, exhibit cortisol elevations in response to brief separation from their pairmate (Mendoza \& Mason, 1986a, 1986b). Previous research has found that female squirrel 


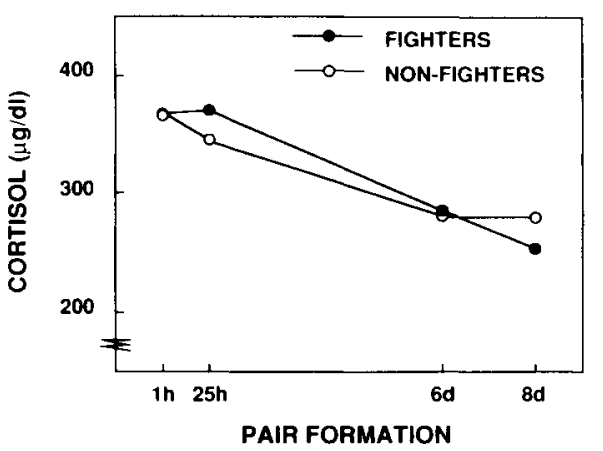

Figure 3. Mean cortisol levels 1 h, 25 h, 6 days, and 8 days following formation of new isosexual pairs for female squirrel monkeys that fought $(n=6)$ and those that did not fight $(n=6)$ with one another.

monkeys, however, do not respond to brief peer separation with increased adrenocortical activity (Hennessy, 1986; Hennessy et al., 1982). Moreover, behavioral studies of social preferences in larger mixed-sex groups suggest that female-female relationships tend to be unstable over time (Tabor, 1986). Indeed, adult females will interact as readily with a like-sex stranger as with a familiar female companion (Saltzman, 1991). Therefore, female squirrel monkeys are highly attracted to one another and they tend to interact affiliatively, but they apparently do not form specific or enduring social attachments with one another.

The results of the present study concur with these findings in that females did not respond to peer separation with an immediate increase in adrenocortical activity. On the contrary, we found a decline in plasma cortisol levels immediately following separation from a familiar cagemate. This has not been observed previously. This finding was unexpected, and methodological differences may account for the apparent discrepancies. Considerable care was taken in the present study to minimize any effects of disturbance that the separation procedures per se may have had on adrenocortical activity. The lack of a detectable response to the disturbance procedures during the control phase indicates that responsiveness to capture and handling did not influence our results. Moreover, the separations were accomplished without placing either animal in novel surroundings. Since novelty is a potent elicitor of adrenocortical activity (Hennessy \& Levine, 1978), it is quite possible that novelty masked an immediate reduction in adrenocortical activity in our previous research.

Another possible explanation for the immediate reduction in adrenocortical activity following separation is that cortisol values from the control phase may have been artifactually elevated. Resting cortisol levels obtained on Day 5 of the control phase were higher than on Day 1, or following the disturbance procedures. Although differences between the control phase cortisol levels were not significantly different from one another, inclusion of the second basal values in calculating control phase means clearly elevated the control values used in these analyses. Separate comparisons of each of the control phase values with the 1-h response to separation indicated that only cortisol levels obtained on Day 5 of the control phase were significantly higher than those obtained $1 \mathrm{~h}$ following separation. Inasmuch as there was no record of any disturbance to the colony room prior to collection of blood samples on Day 5 of the control phase (nor could we deduce any other reasonable explanation for these high levels), we could not justify excluding these samples from the control phase comparisons. Therefore, replication of these results is necessary before we can confidently conclude that separation from familiar female companions actually produces a short-term reduction in adrenocortical activity in adult female squirrel monkeys.

Regardless of whether or not female squirrel monkeys show an immediate decline in adrenocortical activity upon separation from peers, prolonged separation produced a distinctly different outcome-a gradual and significant increase in cortisol levels. The observed elevation does not appear to be attributable to a shift in the circadian cycle, since sampling occurred near the time of the normal circadian peak for plasma cortisol levels of group-housed and individually housed squirrel monkeys (Mendoza, Saltzman, Lyons, \& Schiml, 1991). The slowly developing nature of this response to separation suggests that it is of the type delineated by Hofer $(1978,1987)$ as reflecting the removal of homeostatic regulatory influences. To our knowledge, the present results are the first to document the occurrence of such physiological effects of separation in fully mature animals.

As with the response to separation, the immediate response to pair formation was distinctly different from the prolonged response to pair formation. One hour following pair formation, cortisol concentrations were higher than they had been several days earlier, 6-8 days postseparation. Because cortisol levels had stabilized by the 6th day of separation, this increase does not appear to reflect a continuing elevation of cortisol levels following the initial separation. Furthermore, since the disturbance procedures had no effect on cortisol levels, the disturbance involved in rehousing does not appear to have been a factor. Rather, the initial cortisol elevation seems to have been a transitory response to the introduction of the other female.

On the basis of earlier studies in which cortisol responses to pair formation were assessed either several days following pairing or $1 \mathrm{~h}$ following presentation of a female behind a barrier, it was suggested that pair formation does not produce cortisol elevations in female squirrel monkeys (Mendoza \& Mason, 1986a; Mendoza \& Mason, 1991). The present results, together with these earlier studies, suggest instead that actual interaction between newly paired females leads to an initial increase in cortisol levels. By the 6th day following pairing, however, cortisol levels had declined significantly from those obtained $1 \mathrm{~h}$ following pair formation. Moreover, mean values 6-8 days following pair formation were signifi- 
cantly lower than cortisol levels 6-8 days following separation. Because the newly paired females were unfamiliar with each other, the cortisol decline cannot be attributed to the reinstatement of an affectional bond. Furthermore, there was no evidence that the decline was associated with an increase in affiliation between pairmates. In fact, the primary affiliative behavior shown by squirrel monkeyshuddling-exhibited a pattern opposite to that expected if the reduction in cortisol levels was related to an increase in affiliation: huddling occurred most frequently in the first 3 days following pair formation when cortisol levels were highest. Furthermore, this period of peak cortisol levels occurred before any fighting was observed, and the pairs that were and were not observed to fight showed similar patterns of cortisol decline. Finally, the decline in cortisol levels was not associated with a reduction in locomotor activity.

Overall, these results support the hypothesis that the presence of female partners exerts a downward regulatory influence on circulating cortisol levels of adult female squirrel monkeys, irrespective of the degree of affiliation between the animals (Mendoza, Lyons, \& Saltzman, 1991). In nature, female squirrel monkeys typically reside in multifemale groups (Baldwin, 1985) and occasionally transfer between groups (Boinski, 1987). The downward regulation of adrenocortical activity presumably would be evident as long as females were living in a social group. The increase in cortisol following separation from other females may function to support behavioral changes required when females are in the process of transferring between social groups. For example, glucocorticoid-induced changes in the hippocampus can facilitate extinction of learned patterns of passive and active avoidance and increase exploratory behavior (McEwen, de Kloet, \& Rostene, 1986). It is also possible that reduced cortisol in group-living squirrel monkeys may serve a reproductive function. Because cortisol administration has been shown to block preovulatory release of LH in various species (Moberg, 1985; Moberg, Watson, \& Hayashi, 1982), it may be that female regulation of cortisol levels contributes to breeding readiness in the squirrel monkey (Mendoza \& Mason, 1991).

In Hofer's (1987) work with infant rats, slowly emerging physiological effects of maternal separation appear to be due to the removal of very specific forms of stimulation (e.g., olfactory cues, or gastric filling with milk). This specificity is viewed as a characteristic of regulatory influences that helps distinguish them from effects due to the removal of an attachment figure (Hofer, 1987). In contrast, for adult squirrel monkeys it has been suggested that generic or categorical attributes of social partners serve to regulate neuroendocrine activity (Mendoza, Lyons, \& Saltzman, 1991; Mendoza \& Mason, 1991). Whether these generic attributes can be traced to specific forms of stimulation (e.g., olfactory) is not known. However, it seems reasonable that social partners could exert regulatory influences through multiple sensory modalities that would, nonetheless, be independent of any affiliative or attachment process. It also bears noting that we cannot be certain that the cortisol changes observed here result from overall alterations in the activity of the HPA axis. It is possible that the cortisol effects are mediated neurally (Holzwarth, Cunningham, \& Kleitman, 1987), or by other hormones (e.g., oxytocin), influencing the HPA axis at some level. Future examination of CRH and ACTH following separation and pair formation would be helpful in this regard.

In summary, the present findings suggest that social separation of adult primates can produce physiological changes due to the removal of homeostatic regulatory influences normally provided by other social companions. Thus, the class of separation effects Hofer (1987) identified and studied in preweaning rats is not specific to infants of altricial species. Rather, social regulation of physiological processes may be an essential component of certain adult relationships as well. Since these slowly developing effects of separation are longer lasting and more pervasive than immediate reactive changes, it is likely that removal of regulatory influences, where they exist, will have at least as great an impact on pathophysiological effects following disruption of relationships as loss of emotional support provided by specific social companions. Because prolonged elevations of circulating cortisol levels may have suppressive effects on immunological functioning (Cohen \& Crnic, 1982), the present results also suggest a potential regulatory mechanism by which loss of adult social partners may exert pathophysiological consequences.

\section{REFERENCES}

BALDWIN, J. D. (1985). The behavior of squirrel monkeys (Saimiri) in natural environments. In L. A. Rosenblum \& C. L. Coe (Eds.), Handbook of squirrel monkey research (pp. 35-53). New York: Plenum.

BARnetT, S. A. (1975). The rat (2nd ed.). Chicago: University of Chicago Press.

BassetT, J. M., Hinks, N. T. (1969). Microdetermination of corticosteroids in ovine peripheral plasma: Effects of venipuncture, corticotrophin, insulin, and glucose. Journal of Endocrinology, 44, $387-403$.

BoINSKI, S. (1987). Mating patterns in squirrel monkeys (Saimiri oerstedi). Behavioral Ecology \& Sociobiology, 21, 13-21.

Coe, C. L., Mendoza, S. P., Davidson, J. M., Smith, E. R., Dallman, M. F., \& Levine, S. (1978). Hormonal response to stress in the squirrel monkey (Saimiri sciureus). Neuroendocrinology, 26, 367-377.

Coe, C. L., Mendoza, S. P., Smotherman, W. P., Levine, S. (1978). Mother-infant attachment in the squirrel monkey: Adrenal response to separation. Behavioral Biology, 22, 256-263.

Coe, C. L., Rosenblum, L. A. (1974). Sexual segregation and its ontogeny in squirrel monkey social structure. Joumal of Human Evolution, 3, 1-11

Coe, C. L., Wiener, S. G., Rosenberg, L. T., Levine, S. (1985). Endocrine and immune responses to separation and maternal loss in nonhuman primates. In M. Reite \& T. Field (Eds.), The psychobiology of attactument and separation (pp. 163-199). Orlando: Academic Press.

COHEN, J. J., \& CRNIC, L. S. (1982). Glucocorticoids, stress, and the immune response. In D. R. Webb (Ed.), Immunopharmacology and the regulation of leukocyte function (pp. 61-91). New York: Marcel Dekker. 
Cubicciotti, D. D., III, Mendoza, S. P., Mason, W. A., SassenRATH, E. N. (1986). Differences between Saimiri sciureus and $\mathrm{Cal}$ licebus moloch in physiological responsiveness: Implications for behavior. Journal of Comparative Psychology, 100, 385-391.

Fairbanks, L. (1974). An analysis of subgroup structure and process in a captive squirrel monkey (Saimiri sciureus) colony. Folia Primatologica, 21, 209-224.

HeNNESSY, M. B. (1986). Effects of social partners on pituitary-adrenal activity during novelty exposure in adult female squirrel monkeys. Physiology \& Behavior, 38, 803-807.

HenNessy, M. B., \& Levine, S. (1978). Sensitive pituitary-adrenal responsiveness to varying intensities of psychological stimulation. Physiology \& Behavior, 21, 295-297.

Hennessy, M. B., Mendoza, S. P., \& Kaplan, J. N. (1982). Behavior and plasma cortisol following brief peer separation in juvenile squirrel monkeys. American Journal of Primatology, 3, 143-151.

HENNESSY, M. B., RITCHEY, R. L. (1987). Hormonal and behavioral attachment responses in infant guinea pigs. Developmental Psychobiology, 20, 613-625.

HenNessy, M. B., \& WeinBerg, J. (1990). Adrenocortical activity during conditions of brief social separation in preweaning rats. Behavioral \& Neural Biology, 54, 42-55.

HoFer, M. A. (1978). Hidden regulatory processes in early social relationships. In P. P. G. Bateson \& P. H. Klopfer (Eds.), Perspectives in ethology: Social behavior (Vol. 3, pp. 135-166). New York: Plenum.

HoFER, M. A. (1983). On the relationship between attachment and separation processes in infancy. In R. Plutchik \& H. Kellerman (Eds.), Emotion - Theory, research and experience: Emotions in early development (pp. 199-219). New York: Academic Press.

HoFer, M. A. (1984a). Early stages in the organization of cardiovascular control. Proceedings for the Society for Experimental Biology \& Medicine, 175, 147-157.

HOFER, M. A. (1984b). Relationships as regulators: A psychobiologic perspective on bereavement. Psychosomatic Medicine, 46, 193-197.

Hofer, M. A. (1987). Shaping forces within early social relationships. In N. A. Krasnegor, E. M. Blass, M. A. Hofer, \& W. P. Smotherman (Eds.), Perinatal development: A psychobiologic perspective (pp. 251-274). Orlando: Academic Press.

Holzwarth, M. A., Cunningham, L. A., Klettman, N. (1987). The role of adrenal nerves in the regulation of adrenocortical functions. Annals of the New York Academy of Sciences, 512, 449-464.

House, J. S., LANDIS, K. R., \& UMBerson, D. (1988). Social relationships and health. Science, 241, 540-545.

Leger, D. W., Mason, W. A., \& Fragaszy, D. M. (1981). Sexual segregation, cliques, and social power in squirrel monkey (Saimiri) groups. Behaviour, 76, 163-181.

Mason, W. A. (1971). Field and laboratory studies of social organization in Saimiri and Callicebus. In L. A. Rosenblum (Ed.), Developments in field and laboratory research (Vol. 2, pp. 107-137). San Diego: Academic Press.

MCEWEn, B. S., De KLOET, E. R., \& Rostene, W. (1986). Adrenal steroid receptors and actions in the nervous system. Physiological Reviews, 66, 1121-1188.

Mendoza, S. P., Coe, C. L., Smotherman, W. P., Kaplan, J., \& LEVINE, S. (1980). Functional consequences of attachment: A comparison of two species. In R. W. Bell \& W. P. Smotherman (Eds.), Maternal influences and early behavior (pp. 235-252). Jamaica, NY: Spectrum.

Mendoza, S. P., Lyons, D. M., Saltzman, W. (1991). Sociophysiology of squirrel monkeys. American Journal of Primatology, 23, 37-54.

Mendoza, S. P., \& Mason, W. A. (1986a). Contrasting responses to intruders and to involuntary separation by monogamous and polygynous New World monkeys. Physiology \& Behavior, 38, 795-801.

Mendoza, S. P., \& Mason, W. A. (1986b). Parental division of labour and differentiation of attachments in a monogamous primate (Callicebus moloch). Animal Behaviour, 34, 1336-1347.

Mendoza, S. P., Mason, W. A. (1991). Breeding readiness in squirrel monkeys: Female-primed females are triggered by males. Physiology \& Behavior, 49, 471-479.

Mendoza, S. P., Saltzman, W., Lyons, D. M., Schiml, P. A. (1991). Social influences on seasonal and circadian rhythms in adrenocortical activity of squirrel monkeys. American Journal of Primatology, 24, 122.

Mendoza, S. P., Saltzman, W., Lyons, D. M., Schiml, P. A., \& MAson, W. A. (1991). Within-sex relationships in squirrel monkeys regulate pituitary-adrenal activity. In A. Ehara, T. Kimura, O. Takenaka, \& M. Iwamoto (Eds.), Primatology today (pp. 443446). Amsterdam: Elsevier.

Mendoza, S. P., Smotherman, W. P., Miner, M. T., Kaplan, J., \& LEviNe, S. (1978). Pituitary-adrenal response to separation in mother and infant squirrel monkeys. Developmental Psychobiology, 11, 169-175.

MinekA, S., \&uOMi, S. J. (1978). Social separation in monkeys. Psychological Bulletin, 85, 1376-1400.

Moberg, G. P. (1985). Influence of stress on reproduction: Measure of well-being. In G. P. Moberg (Ed.), Animal stress (pp. 245-267). Bethesda: American Physiological Society.

Moberg, G. P., Watson, J. G., Hayashi, K. T. (1982). Effects of adrenocorticotropin treatment on estrogen, luteinizing hormone, and progesterone secretion in the female rhesus monkey. Journal of Medical Primatology, 11, 235-241.

O'LeARY, A. (1990). Stress, emotion, and human immune function. Psychological Bulletin, 108, 363-382.

Panksepp, J., Siviy, S. M., Normansell, L. A. (1985). Brain opioids and social emotions. In M. Reite \& T. Field (Eds.), The psychobiology of attachment and separation (pp. 3-49). New York: Academic Press.

Reite, M., Kaufman, I. C., Pauley, J. D., Stynes, A. J. (1978). Depression in infant monkeys: Physiological correlates. Psychosomatic Medicine, 36, 363-367.

SAltzmAn, W. (1991). Social relationships among squirrel monkeys (Saimiri sciureus): Context, Dynamics, and Physiological Consequences. Unpublished doctoral dissertation, University of California, Davis.

Saltzman, W., Mendoza, S. P., \& Mason, W. A. (1991). Sociophysiology of relationships in squirrel monkeys: I. Formation of female dyads. Physiology \& Behavior, 50, 271-280.

ShaPiRo, L. E., \& INSEL, T. R. (1990). Infant's response to social separation reflects adult differences in affiliative behavior: $\mathrm{A}$ comparative developmental study in prairie and montane voles. Developmental Psychobiology, 23, 375-393.

Smotherman, W. P., Hunt, L. E., McGinnis, L. M., \& Levine, S. (1979). Mother-infant separation in group living rhesus macaques: Hormonal analysis. Developmental Psychobiology, 12, 211-217.

TABOR, B. A. (1986). The development and structure of Saimiri social relationships. Unpublished doctoral dissertation, University of California, Davis.

Tamborski, A., Lucot, J. B., \& Hennessy, M. B. (1990). Central dopamine turnover in guinea pig pups during separation from their mothers in a novel environment. Behavioral Neuroscience, 104 607-611.

(Manuscript received December 9, 1991; revision accepted for publication August 4, 1992.) 